Dear author,

Please note that changes made in the online proofing system will be added to the article before publication but are not reflected in this PDF.

We also ask that this file not be used for submitting corrections. 
Note: These proofs may contain color figures. Those figures may print black and white in the final printed book if a color print product has not been planned. The color figures will appear in color in all electronic versions of this book.

\section{AUTHOR QUERY FORM}

E-mail: s.jakeman@elsevier.com

Dear Author

Any queries or remarks that have arisen during the processing of your manuscript are listed below and are highlighted by flags in the proof. (AU indicates author queries; ED indicates editor queries; and TS/TY indicates typesetter queries.) Please check your proof carefully and answer all AU queries. Mark all corrections and query answers at the appropriate place in the proof using on-screen annotation in the PDF file. For a written tutorial on how to annotate PDFs, click http://www.elsevier.com/_data/assets/pdf_file/0007/98953/Annotating-PDFs-AdobeReader-9-X-or-XI.pdf. A video tutorial is also available at http://www.screencast.com/t/9OIDFhihgE9a. Alternatively, you may compile them in a separate list and tick off below to indicate that you have answered the query.

Please return your input as instructed by the project manager.

Uncited references: References that occur in the reference list but are not cited in the text. Please position each reference in the text or delete it from the reference list.

Missing references: References listed below were noted in the text but are missing from the reference list. Please make the reference list complete or remove the references from the text.

\begin{tabular}{|c|c|}
\hline Location in Article & Query / remark \\
\hline AU:1, Page 655 & $\begin{array}{l}\text { This sentence "Annual liver ultrasound..." has been reworded/modified for clarity. Please check if } \\
\text { the intended meaning is not altered. }\end{array}$ \\
\hline AU:2, Page 656 & $\begin{array}{l}\text { This sentence "Clearly, also an interdisciplinary..." has been reworded/modified for clarity. } \\
\text { Please check if the intended meaning is not altered. }\end{array}$ \\
\hline AU:3, Page 657 & $\begin{array}{l}\text { This sentence "TG is a glomerular lesion..." has been reworded/modified for clarity. Please check } \\
\text { if the intended meaning is not altered. }\end{array}$ \\
\hline AU:4, Page 657 & $\begin{array}{l}\text { This sentence "The rate of acute rejection..." has been reworded/modified for clarity. Please check } \\
\text { if the intended meaning is not altered. }\end{array}$ \\
\hline AU:5, Page 658 & $\begin{array}{l}\text { This sentence "In HCV-positive KT recipients..." has been reworded/modified for clarity. } \\
\text { Please check if the intended meaning is not altered. }\end{array}$ \\
\hline AU:6, Page 659 & $\begin{array}{l}\text { This sentence "This suggests that an..." has been reworded/modified for clarity. Please check if the } \\
\text { intended meaning is not altered. }\end{array}$ \\
\hline AU:7, Page 659 & $\begin{array}{l}\text { This sentence "Beside the use of first generation..." has been reworded/modified for clarity. } \\
\text { Please check if the intended meaning is not altered. }\end{array}$ \\
\hline AU:8, Page 660 & $\begin{array}{l}\text { The given sentence seems to be incomplete "Simeprevir, a specific NS3...". Please check for missing } \\
\text { words/phrases and complete the sentence. }\end{array}$ \\
\hline AU:9, Page 660 & $\begin{array}{l}\text { This sentence "Their results, expected by the..." has been reworded/modified for clarity. } \\
\text { Please check if the intended meaning is not altered. }\end{array}$ \\
\hline
\end{tabular}




\title{
Kidney Transplantation in the Hepatitis C Infected Recipient
}

\author{
Roberta Angelico, Giuseppe Iaria and Mario Angelico \\ Tor Vergata University Hospital, Rome, Italy
}

\subsection{INTRODUCTION}

Chronic hepatitis C (HCV) infection is a leading cause of chronic liver disease worldwide, with a global preva- p0010 lence rate of around $3 \% .{ }^{1}$ The prevalence of HCV infection is much higher in patients with chronic renal disease compared to the general population: approximately $6 \%$ of patients with end-stage renal disease (ESRD) on chronic replacement therapy ${ }^{2}$ are infected with $\mathrm{HCV}$, between $4 \%-70 \%$ of patients on hemodialysis (HD), and $11 \%-49 \%$ of kidney transplant $(\mathrm{KT})$ recipients. ${ }^{3-5}$

In the KT population, chronic HCV infection course is accelerated compared to the general population, being p0015 associated with a significant reduction in patient and graft survival. ${ }^{6-8}$ The unfavorable impact of HCV infection on KT survival is likely related to liver fibrosis progression induced by the use of immunosuppressive regimens, which accelerates fibrogenesis and worsens the liver damage. ${ }^{9-13}$ Recent evidence also suggests that chronic $\mathrm{HCV}$ infection is an independent risk factor for acute and chronic rejection, graft glomerulopathy, posttransplant new-onset diabetes and HCV-related glomerulonephritis in KT recipients. ${ }^{14-15}$

Patients with an active HCV infection have a reduced long-term survival, which is associated with increased p0020 morbidity and mortality as compared with patients without HCV infection, mainly as a consequence of cardiovascular disease, or secondary to infections and liver disease. However, the overall survival appears to be better in KT patients compared to those remaining on dialysis, which highlights the importance of managing $\mathrm{HCV}$ infection, as well as HCV-related liver disease in these patients. ${ }^{16}$

The management of HCV infection in KT recipient presents unique challenges. The two main factors p0025 influencing the graft outcome are the use of antiviral therapy and immunosuppressive drugs. Before the introduction of the new directly acting antiviral (DAA) drugs, the possibility to treat of HCV infection with interferon- $\alpha$ (IFN- $\alpha)$ and ribavirin (RBV) was limited by the higher renal allograft rejection rates and the related drug toxicity. ${ }^{17-19}$ Therefore, all HCV-infected KT candidates should be evaluated for potential antiviral therapy before transplantation. Viral eradication before transplant may not only lower the risk of progressive liver disease after $\mathrm{KT}$, but also of $\mathrm{HCV}$-associated extrahepatic complications. No consensus has yet been reached about the optimal immunosuppressive strategy to be used in HCV-positive KT recipients. $^{20}$

Combined kidney-liver transplantation is currently also considered a valid option in patients with liver p0030 cirrhosis. ${ }^{21-22}$ Moreover, transplantation of kidneys from HCV-positive donors to HCV-positive recipients is currently considered to be a safe long-term approach and a strategy to improve the donor pool and to reduce the waiting list for transplantation. ${ }^{23}$ 


\subsection{EPIDEMIOLOGY AND RISK FACTORS OF HCV INFECTION IN PATIENTS WITH CHRONIC RENAL DISEASE}

HCV infection is highly prevalent in patients with ESRD undergoing HD and represents the main cause of p0035 liver disease in this population, although in recent years the prevalence has been reduced by almost one third. $^{24-25}$ The prevalence varies among different regions, with a higher frequency in developing countries (approximately 75\%-80\%) than in developed regions (approximately 3.4\%). ${ }^{26-28}$ Despite the elimination of posttransfusion HCV transmission due to the beginning of HCV screening in the early 1990s, the incidence of HCV infection among patients on chronic treatment dialysis remains relatively high, with seroconversion rates ranging between $0.2 \%$ and $15 \%$ per year of dialysis. ${ }^{29}$

Patients under renal hemodialysis are exposed to blood-borne pathogens due to the need for intravenous p0040 access and frequent catheter manipulations. Although prospective trials have shown a reduction in HCV transmission within dialysis units through the complete isolation of HCV patients, this practice has not been universally accepted. ${ }^{30}$ The Kidney Disease: Improving Global Outcomes (KDIGO) panel does not recommend the use of dedicated machines, patient isolation, or a ban on reuse in HCV patients on HD. However, strict adherence to "universal precautions," careful attention to hygiene, and sterilization of machine dialysis is emphasized. While transfusion of blood product still plays a significant epidemiological role in developing countries, the majority of $\mathrm{HCV}$ infections in the hemodialysis setting are currently attributed to nosocomial transmission through handborne transmission, or to the use of concomitant medication vials, such as saline, anesthetic drugs, and unfractionated heparin. ${ }^{31-33}$ A systematic review of 20 studies analyzing the possible transmission routes reported that the cross-contamination from supplies and surfaces, resulting from failure of local sanitary infection-control practices, seems to be the main factor for HCV transmission. ${ }^{34}$

The risk factors for acquiring HCV infection during dialysis include the following: number of transfusions, p0045 duration of dialysis, previous transplant, number of procedures for dialysis access, type of dialysis (the incidence in HD is higher then in peritoneal dialysis), prevalence of HCV infection in dialysis unit. ${ }^{35-36}$ Therefore, the prevalence of $\mathrm{HCV}$ infection in KT recipients varies widely (from $6 \%$ to $46 \%$ ). In most HCV-positive KT recipients, the infection occurs before transplant, while patients are on HD, whereas only exceptionally the acquisition of $\mathrm{HCV}$ infection occurs through an infected donor and is infrequently acquired after KT. ${ }^{37}$

\subsection{SCREENING AND DIAGNOSIS OF HCV INFECTION IN PATIENTS WITH ESRD}

\subsubsection{Before Kidney Transplantation}

Baseline screening in dialysis patients includes serological assays for antibodies to HCV (anti-HCV) and serum p0050 alanine aminotransferase (ALT) levels. Currently third- and fourth-generation anti-HCV enzyme-linked immunoassays yield very high sensitivity rates, up to $100 \%$, in immunocompetent patients. However, the "serological window" between acute infection and the detection of specific antibodies takes an average of 8 weeks, and in immunocompromised patients, antibody production may be delayed or absent, resulting in false-negative antiHCV. ALT levels in patients with chronic renal dysfunction have been reported to be lower than in the general population, possibly due to suppression of ALT synthesis in hepatocytes, defective release of ALT into the blood stream, or accelerated clearance in patients with chronic renal insufficiency. ${ }^{38-40}$

For anti-HCV-negative patients, the recommendation is to monitor ALT levels monthly, and anti-HCV every 6 p0055 months. ${ }^{41}$ Increases in ALT levels should prompt testing for HCV infection, and if anti-HCV is negative despite persistently increased ALT levels, testing for HCV-RNA should be considered and repeated, if negative. This is especially important in patients on dialytic therapy, in whom low and fluctuating viremia might happen, resulting in undetectable viremia despite the presence of the virus.

For anti-HCV positive patients, HCV-RNA testing should always be performed. A positive result confirms p0060 infection, either acute (defined as the presence of HCV-RNA for $<6$ months) or chronic (defined as persistence of HCV-RNA > 6 months). A negative result is considered as a resolved HCV infection, or a false-positive antibody test. However, isolated undetectable results of HCV-RNA should not be interpreted as absence of replication. It is recommended for all anti-HCV positive patients on HD to perform sequential HCV-RNA monitoring, by using highly sensitive detection methods, like reverse transcriptase-polymerase chain reaction (RT-PCR) or transcription-mediated amplification. ${ }^{42-43}$ HCV-RNA PCR-based molecular diagnostics are required also to 
measure the viral load and identify the HCV genotype, in order to guide management decisions and monitoring the response to antiviral therapy.

During HD, HCV-RNA level is transiently decreased and gradually returns to baseline level within 48 hours. p0065 This may be explained by several mechanisms, such as interference with PCR technique by adsorption of HCV onto the dialysis membrane, heparin use during dialysis, destruction of HCV particles by the hydraulic pressure, hepatocyte growth factor, or increased plasma IFN levels during the dialysis. Therefore, it is recommended to determine HCV-RNA level before HD to avoid the possibility of underestimation. ${ }^{40,44}$

"Occult HCV infection," a new entity defined by detection of HCV-RNA in peripheral blood mononuclear cells p0070 (PBMC) and/or hepatocytes in the absence of HCV-RNA in serum, has been a matter of controversy. ${ }^{6}$ Occult infection, which is not detectable by routine diagnostic methods, may also represent a risk for nosocomial transmission of $\mathrm{HCV}$ infection in dialysis units, as well as an additional risk for virus reactivation and progression of liver disease after KT. However, a recent study evaluating 417 hemodialytic subjects found only one single case $(<1 \%)$ of occult HCV infection in PBMC, suggesting that this condition is indeed very rare in ESRD in HD. ${ }^{45}$

\subsubsection{After Kidney Transplantation}

In most HCV-positive KT recipients the infection occurs before transplantation, while patients were on HD. p0075 Therefore, HCV-positive recipients are often already assessed for HCV infection at the time of transplant. After $\mathrm{KT}$, levels of HCV-RNA rise, as a consequence of immunosuppressive therapy. ${ }^{46}$ A percentage of KT recipients are HCV-RNA positive, but anti-HCV negative; the reason remains still unclear, but is probably due to the inability to mount an antibody response against HCV due to the immunosuppressive drugs. ${ }^{47-49}$ There are few data to suggest when and how to screen HCV-infected KT recipients. However, given the higher level of immunosuppression early after transplantation, the KDIGO suggested that liver enzymes should be checked every month for the first 6 months of the posttransplant period, and every 3 months thereafter. ${ }^{20}$

$\mathrm{HCV}$ has also been implicated in the pathogenesis of glomerular disease in both native and transplanted kid- p0080 neys. Therefore, the Hepatitis C and Transplant Guideline Working Group concluded that HCV-infected KT recipients should be tested for proteinuria every 3-6 months. As recommended for all KT recipients, patients who develop new-onset proteinuria (either urine protein/creatinine ratio $>1$ or 24-hour urine protein greater than $1 \mathrm{~g}$ on two or more occasions) should have an allograft biopsy with immunofluorescence and electron microscopy. ${ }^{20}$

\subsection{EVALUATION OF THE HCV-RELATED LIVER DISEASE}

The evaluation of the stage of liver disease in HCV-positive KT candidates and recipients is important in p0085 determining the risk for liver-related complications. The assessment of liver disease should include clinical examination, laboratory testing and ultrasound for radiological signs of cirrhosis/portal hypertension and hepatocellular carcinoma. However, ultrasound only shows moderate sensitivity in detecting liver cirrhosis, ${ }^{50}$ and the level of transaminases may not reflect the severity of the liver disease, or may even be normal in cirrhosis. ${ }^{51,52}$ The detection of worsening liver enzymes should prompt referral for a hepatological evaluation. Annual liver ultrasound and assay of alpha-fetoprotein levels to screen for hepatocellular carcinoma should also be considered for all HCV patients, either before or after KT.

Liver biopsy is the gold standard for assessing the degree of fibrosis in HCV-positive patients on HD, as well p0090 as in transplant recipients. ${ }^{53}$ Studies have demonstrated that the prevalence of advanced fibrosis and cirrhosis in liver biopsies ranges from $10 \%$ up to $25 \%$ in KT candidates with HCV infection. ${ }^{52}$ However, its use is limited by the invasive nature, poor patient acceptance, bleeding risk, especially in uremic patients, with additional risks in patients who need invasive procedure. ${ }^{54}$ Transjugular liver biopsy is an alternative procedure for obtaining liver specimens instead of a percutaneous approach. ${ }^{55}$ The advantage of this procedure is due to a greater safety and the possibility of the simultaneous measurement of the hepatic venous pressure gradient (HVPG), which provides relevant prognostic information in patients with compensated liver cirrhosis (a HVPG $\geq 10 \mathrm{mmHg}$ indicates the presence of a clinically significant portal hypertension). However, this procedure is not widely available and frequently provides small tissue samples, which might underestimate fibrosis staging.

The need of noninvasive tests to estimate the liver fibrosis in HCV patients has become critical in recent years. p0095 Imaging tests, such as transient elastography (FibroScan; Echosens, Paris, France) or blood-based tests, such as AST-to-platelet ratio index (APRI) have shown good diagnostic performance to predict the severity of liver 
fibrosis in the ESRD population. ${ }^{56-58}$ Results from a meta-analysis of 40 studies showed that an APRI cut-off of 1.0 had a sensitivity of $76 \%$ and a specificity of $72 \%$ for predicting cirrhosis. Similarly, an APRI cut-off of 0.7 had a sensitivity of $77 \%$ and a specificity of $72 \%$ for predicting significant hepatic fibrosis. ${ }^{59}$ However, transient elastography shows superior diagnostic accuracy compared to APRI in HCV patients with ESRD. ${ }^{60}$ Yet, although these methods have been shown to be reliable for the diagnosis of cirrhosis, they are less accurate than liver biopsy in discriminating different fibrosis stages. ${ }^{61}$

Although there is no current agreement regarding the optimal test to estimate liver fibrosis in HCV patients p0100 before and after $\mathrm{KT}$, we suggest that before transplantation the liver biopsy should remain the gold standard; after transplantation, serial transient elastography measurements may be relevant for surveillance of fibrosis progression, in particular in recipients with contraindications to liver biopsy, or in those who refuse to be biopsied, though this remains to be evaluated in further prospective studies. ${ }^{52}$ Clearly, also an interdisciplinary management by a nephrologist and a hepatologist is essential, either before or after KT.

\subsection{NATURAL HISTORY OF HCV INFECTION IN PATIENT WITH END-STAGE RENAL DISEASE}

The natural history of HCV infection in HD patients tends to have a mild course. ${ }^{62-63}$ Several explanations p0105 have been proposed, including the presence of an altered immunologic state and the relatively low HCV viral load commonly observed in the HD population. ${ }^{38-40}$ In patients with ESRD, HCV infection has distinct clinical and laboratory features as compared to the general population and KT recipients; ALT levels and HCV viral loads are lower then those observed in nonuremic patients, even in the presence of significant histological damage. The prevalence of advanced liver fibrosis is lower (4\%-10\%) and progression to cirrhosis during HD seems to be uncommon. ${ }^{64-65}$

Despite this, the unfavorable impact of HCV-related liver disease on mortality in patients with ESRD has been p0110 well documented. Infected patients have a $25 \%$ increased risk of mortality on HD compared with HCV-negative subjects. ${ }^{66-67}$ In the last decades, meta-analyses demonstrated that the presence of anti-HCV antibody in the HD population represents an independent significant risk factor for death. ${ }^{68}$ Interestingly, in the ESRD setting, the increased mortality in $\mathrm{HCV}$-positive versus $\mathrm{HCV}$-negative patients is due not only to liver-related deaths, but also to cardiovascular mortality. ${ }^{69}$

ESRD candidates to KT with cirrhosis, particularly those with portal hypertension, may have a decreased sur- p0115 vival and increased morbidity after KT. Therefore, patients with cirrhosis, but without significant portal hypertension, should be evaluated for isolated KT; however, in candidates with advanced fibrosis or cirrhosis, liver imaging monitoring and upper endoscopy are recommended for the screening of hepatocellular carcinoma and esophageal varices, respectively. If signs of decompensated cirrhosis occur, KT alone is contraindicated and combined liver-kidney transplantation should be considered. ${ }^{21,22}$

\subsection{NATURAL HISTORY OF HCV INFECTION AFTER KT}

Several studies reported that HCV infection is associated with increased liver-related mortality and fibrosis p0120 progression in HCV-infected KT patients, with a significant reduction in patient and graft survival. This is possibly related to an accelerated progression of HCV-related liver disease, but also to an unfavorable effect of HCV infection in the challenging KT recipient setting, due to the increased risk of graft rejection and glomerulopathy, new-onset diabetes, HCV-related glomerulonephritis and posttransplant malignancy. Therefore, clinical consequences of HCV infection after KT can be classified as renal disease induced by HCV infection, and hepatic and extrahepatic complications.

\subsubsection{Renal Disease Induced by HCV After KT}

Glomerular lesions have been described in native and transplanted kidneys of patients with HCV infection. ${ }^{70}$ p0125 After KT, new-onset or recurrence of membranoproliferative glomerulonephritis (MPGN), with or without 
cryoglobulinemia, membranous glomerulonephritis, acute or chronic transplant glomerulopathy (TG), and anticardiolipin-associated thrombotic microangiopathy have been described. ${ }^{71}$

MPGN is the most frequent glomerular lesion associated with chronic HCV in KT, followed by membranous p0130 glomerulonephritis. The pathogenesis of HCV-associated glomerulonephritis might be explained by an altered antibody to antigen ratio caused by the deposition of immunocomplexes that contain HCV-RNA in the kidneys of immunosuppressed recipients. ${ }^{72}$ This results in immune complex-mediated glomerulonephritis. Notably, $\mathrm{HCV}$-associated glomerulonephritis is unrelated to the severity of liver disease.

\subsubsection{Transplant Glomerulopathy}

TG is a glomerular lesion unique to kidney graft characterized by the duplication/multilayering of the glomer- p0135 AU:3 ular basement membrane, usually thought to be a manifestation of a chronic antibody-mediated rejection. ${ }^{73}$ However, the histological features of TG and HCV-associated MPGN are similar; therefore, an association of $\mathrm{HCV}$ infection and TG was suggested. ${ }^{74}$ One study showed that the prevalence of anti-HCV antibodies was higher in patients with (33\%) than in those without TG $(1.9 \%) .{ }^{75} \mathrm{TG}$ is associated with a poor allograft survival, which seems to be worse if TG is associated with HCV infection. Yet, it is unclear why only few patients with HCV infection develop this complication.

\subsubsection{Acute Graft Rejection}

The effect of HCV infection on the risk of acute rejection is controversial. Some authors observed a decreased p0140 rate of acute rejection in $\mathrm{HCV}$-infected recipients, ${ }^{76}$ which has not been confirmed in other studies. ${ }^{77}$ The rate of acute rejection in patients with HCV infection has been reported to be around $14.5 \%$ over a 20 -year period. In the study by Forman et al., a higher incidence of antibody-mediated acute rejection was reported at univariate analysis in HCV-positive (19\%) compared to HCV-negative recipients (6\%), but this result was not confirmed to be independent after adjusting for confounding factors. ${ }^{78}$ Another study based on protocol biopsies in 435 recipients obtained within the first 6 months after KT showed that subclinical acute rejection and HCV infection were independent factors of allograft loss. ${ }^{79}$ Based on these data, the relationship between HCV infection and acute renal allograft rejection remains currently unclear.

\subsubsection{Hepatic Complications After KT}

HCV infection is the major cause of liver disease after KT and it is associated with increased mortality (51). p0145 Both the severity and duration of HCV infection and associated comorbidities are determinant for the clinical course. Chronic hepatitis and its possible progression toward cirrhosis are the main forms of liver disease. In addition, a rare but severe form of liver disease known as fibrosing cholestatic hepatitis (FCH), characterized by severe cholestasis and rapidly progressive liver failure, has been reported. ${ }^{80-81}$

The main cause of an accelerated HCV-related disease progression after transplant is the immunosuppressive p0150 regimen, which favors increased fibrogenesis. ${ }^{9-13}$ Recent data suggested that fibrosis progression is faster if HCV infection is acquired during or after KT. ${ }^{82}$ However, fibrosis progression in HCV-positive KT recipients has been reported to be heterogeneous: some studies found an accelerated fibrosis progression, while others suggested a stable histology after the transplant. ${ }^{52,83}$ A possible explanation for these discordant rates of fibrosis progression may be due to the differences in immunosuppressive regimens. Immunosuppression therapy is also associated with a significant increase of $\mathrm{HCV}$ viral load. ${ }^{28}$ However, a high viral load does not necessarily lead to more severe fibrosis in $\mathrm{KT}$ recipients, ${ }^{73}$ except for $\mathrm{FCH}$, which possibly results from direct viral hepatotoxicity due to an extremely high intracellular viral load (70). Interestingly, similarly to HD subjects, there is a very low prevalence of occult $\mathrm{HCV}$ infection in KT recipients. ${ }^{18,19} \mathrm{HCV}$-induced cirrhosis is associated with a high risk of HCC development. HCC incidence may be higher in KT patients compared to the general population, especially in countries with a high prevalence of chronic hepatitis B and C infections. ${ }^{84-86}$ Therefore, as in the pretransplant period, all patients with cirrhosis after transplantation should undergo HCC surveillance by liver ultrasonography every 6 months. ${ }^{50}$

\subsubsection{Extrahepatic Complications After KT}

\subsubsection{New-Onset Diabetes After Transplantation}

The relation of HCV infection to insulin resistance and diabetes mellitus in the general population is well p0155 documented. The pathogenesis of diabetes mellitus in HCV infection mainly involves the development of insulin 
resistance, due to the inhibition of the insulin regulatory pathways induced by HCV infection. ${ }^{16}$ A meta-analysis identified that $\mathrm{HCV}$-positive KT recipients have an increased risk of new-onset diabetes after transplantation (NODAT). ${ }^{87}$ Consequently, NODAT is considered an independent risk factor for death, and may be one of the main factors responsible for the lower patient and graft survival in HCV-positive KT recipients. The association of HCV and NODAT is also influenced by traditional risk factors, such as obesity, old age, ethnicity (Hispanic or Afro-American), and a positive family history of diabetes mellitus. In HCV-positive KT recipients, NODAT usually occurs in the initial months after transplantation, when higher doses of immunosuppressive drugs are usually administered. ${ }^{88}$ Consequently, in these recipients, the use of tacrolimus should be minimized, and steroid-sparing immunosuppressive strategies might be preferable.

\subsubsection{Infections}

The possible association of HCV-related liver disease and other infections after renal transplantation is contra- p0160 dictory. Several studies found a significantly increased risk for infections in HCV-positive recipients during the first 6-12 months after KT. In contrast, a recent meta-analysis reported no differences of secondary infections in $\mathrm{HCV}$-positive compared to recipient $\mathrm{HCV}$-negative patients after $\mathrm{KT}$. $^{13}$ The latter data have been confirmed by a multicenter study, which showed no differences in the overall incidence of infections (bacterial, viral, and fungal) in HCV-recipients, except for bloodstream infections. ${ }^{68}$ Furthermore, in a single retrospective case-control study, $\mathrm{HCV}$ infection was demonstrated to be an independent risk factor for posttransplant tuberculosis. ${ }^{89}$

\subsubsection{Extrahepatic Malignancies}

The association of HCV infection and posttransplant lymphoproliferative disorder and myeloma has been p0165 reported. ${ }^{90-92} \mathrm{~A}$ recent study described that hematological malignancies are the third most common cause of death in patients infected with HCV, supporting the view that HCV infection could have a role in their pathogenesis. ${ }^{93}$ A direct effect of $\mathrm{HCV}$ infection on cancerogenesis of lymphoid cells has also been demonstrated and reports of lymphoma regression after antiviral treatment further support this potential association. ${ }^{94}$ However, the causal relationship remains unclear. Strict surveillance for malignancy in HCV-infected recipients is therefore recommended..$^{20}$

\subsection{IMMUNOSUPPRESSION IN HCV-POSITIVE KT RECIPIENTS}

Immunosuppression in HCV-positive KT recipients is a challenge. The choice of the initial and maintenance p0170 immunosuppressive regimen may in fact be crucial in order to avoid a raise in HCV viral load and an acceleration of HCV-induced progression of liver fibrosis. A further crucial point is the treatment of acute rejection episodes with steroids, which is well known to favor HCV replication. Therefore, the addition of any further immunosuppressive drug always needs to be accurately evaluated, as it is mandatory to choose an immunosuppressive regimen providing an adequate control of both rejection episodes and progression of HCV-related liver damage. Unfortunately, the lack of controlled studies in this setting does not help to support, or deny, any specific immunosuppressive regimen. Therefore, the KDIGO and ERBP guidelines recommend using the conventional immunosuppressive regimens currently given for HCV-negative patients also in HCV-positive recipients. ${ }^{95}$

In vitro studies have shown that Cyclosporine (CsA) may inhibit HCV replication, but in the clinical setting p0175 this antiviral effect remains controversial. ${ }^{96-98}$ The United States Renal Data System (USRDS) registry reported a better graft survival in KT recipients treated with mycophenolate mofetil (MMF), than in those with other immunosuppressive therapy. ${ }^{97}$ Interestingly, the association of MMF and increasing graft survival in HCV-positive recipients has been reported also in the liver transplant setting. Manzia et al., e.g., reported that MMF monotherapy was associated with a favorable effect on biopsy-proven hepatic fibrosis progression in HCV liver transplant recipients, compared with monotherapy with calcineurin inhibitors (CNIs). ${ }^{99}$

Recently, the mammalian target of rapamycin (mTOR) inhibitors, a new class of potent immunosuppressive p0180 drugs, has been ordinarily introduced in immunosuppression regimens after KT. Beyond their immunosuppressive action, both Sirolimus and Everolimus exert antiangiogenic, antiproliferative, and antifibrotic properties. ${ }^{100-103}$ In addition, mTOR inhibitors have been associated with a lower incidence of viral infections. In a recent systematic review and meta-analysis it was reported that CMV prophylaxis might be promoted by the use of mTOR inhibitors. ${ }^{104}$ Recently, Soliman et al. reported that conversion from CNI to sirolimus may suppress viral replication in $\mathrm{HCV}$-positive renal transplant candidates. In a series of $25 \mathrm{HCV}$-positive KT recipients, 10 
46.8 CURRENT PERSPECTIVES OF TREATMENT OF HCV-INFECTED PATIENTS ON HEMODYALISIS AND IN KT RECIPIENTS WITH ANTIVIRALS 659

patients were switched to sirolimus and 15 patients remained under CsA. Patient receiving sirolimus showed a slight decrease in HCV-RNA levels, with similar decreases in serum transaminases, suggesting a possible advantage of sirolimus in this setting. ${ }^{105}$

Despite the limited data available related to the effects of mTOR inhibitors on HCV infection and disease p0185 progression in KT recipients, more data have been reported on the use of these drugs in HCV-positive liver transplant recipients. A recent retrospective study, analyzing 190 patients undergoing first liver transplant for HCVrelated end-stage liver disease over a 15-year period, showed that 113 patients switched from CNIs-based therapy to low-dose sirolimus monotherapy had improved survival $(P<.001)$ and slower progression to cirrhosis $(P=.001){ }^{106}$ Similarly, Kelly et al. observed at the multivariate analysis decreased odds of biopsy-proven hepatic fibrosis 1 year after liver transplantation in recipients who received sirolimus therapy. ${ }^{107}$ Furthermore, in a randomized multicenter, open-label study, 43 liver transplant recipients with recurrent HCV infection were randomized to continue CNI-based immunosuppression or to switch to everolimus. After 1 year, in patients receiving everolimus, the Ishak fibrosis score decreased significantly (by a mean of -0.7), while it slightly increased in patients who continued CNIs, suggesting that conversion to everolimus might be beneficial to control disease progression. $^{108}$

No similar data have been reported in the KT setting. In addition, the mechanisms underlying the possible p0190 favorable effect of mTOR inhibitors on the progression of HCV-related liver disease are still unclear. TGF- $\beta 1$ may exert a crucial role, since it has been identified as a most potent stimulus for hepatic fibrogenesis through activation of hepatic stellate cells. ${ }^{109}$ Of note, a recent paper reported that everolimus decreases the serum expression of fibrosis markers in liver transplant recipients by reducing TGF- $\beta 1$ and hyaluronic acid, an essential component of the extracellular matrix which is mostly synthesized by hepatic stellate cells. ${ }^{110}$ In conclusion, while larger prospective studies are definitely needed to better address the optimal use of new immunosuppressive drugs in $\mathrm{HCV}$-positive KT recipients, current data suggest that mTOR inhibitors may have a greater role in the future.

\subsection{CURRENT PERSPECTIVES OF TREATMENT OF HCV-INFECTED PATIENTS ON HEMODYALISIS AND IN KT RECIPIENTS WITH ANTIVIRALS}

Eradication of HCV infection in patients with ESRD, as well as in KT recipients, is a long-term recognized p0195 unmet clinical need. The rationale for treating HCV before KT is that treatment may avoid not only liver-related mortality, but also HCV-specific causes of kidney graft dysfunction, as discussed above. This suggests that an effective antiviral treatment should be initiated as soon as possible, ideally in the pretransplant setting. Unfortunately, treatment of HCV infection in patients with ESRD, or under HD replacement, with the conventional dual therapy based on peg-interferon alfa (Peg-IFN) and ribavirin has shown a limited efficacy and to be associated with significant side effects. The main limitation is that ribavirin cannot be used at adequate doses in patients with moderate/severe kidney diseases (KD) and in those with ESRD, as it is associated with severe drug-induced hemolytic anemia. As a consequence, in most cases conventional peg-IFN based treatment has been used as monotherapy, or together with very low doses of ribavirin (e.g., $200 \mathrm{mg}$ /day or less). This resulted in sustained virological response (SVR) rates in the range of $20 \%-25 \%$ or less, except in the relatively small number of patients infected with HCV genotype 2. On the other hand, treatment with IFN-based therapies in KT recipients has always been regarded as a too risky approach, because of the fear of inducing acute rejection by IFN administration. Although the extent of this risk has never been formally evaluated, this has de facto discouraged the use of conventional antiviral therapy in KT recipients.

The recent development and availability of DAAs against HCV has brought the enormous potential to change p0200 this unfavorable scenario into a much more promising one. Beside the use of first generation DAAs, telaprevir, and boceprevir, which have rapidly been abandoned because of severe side effects and difficult treatment schedules, the advent of the single-pill second generation DAA sofosbuvir, and of other very effective second generation drugs, has dramatically increased the possibility of cure of HCV infection during the last 2 years. These drugs, either alone or in combination, are capable of eradicating HCV infection in approximately 85\%-95\% of patients with normal renal function, with minor changes mainly depending on the HCV genotype and the extent of liver disease. ${ }^{111}$

Unfortunately, at present no formal data on the safety and efficacy have been published on the use of DAAs p0205 in patients with renal dysfunction, nor in those with ESRD, or in KT recipients. The only available information 
derives from the registration data, which have been used by the international drug agencies (Food and Drug Administration and European Medicine Agency) to allow drug licensing for commercialization. Most registration trials have been conducted in patients with eGFR $>30 \mathrm{~mL} /$ minute, thus most drugs have been currently licensed only for the use in patients with normal renal function.

Sofosbuvir, a specific HCV NS5B mucleosidic inhibitor, which is the most currently-used drug, at a dose of p0210 $400 \mathrm{mg} /$ daily, is predominantly renally excreted $(>80 \%)$. It is found in urine mostly as the dephosphorylated metabolite GS-331007. Because of the predominant renal excretion and the expected high drug or metabolite exposure in the presence of severe renal impairment, sofosbuvir is not currently recommended in patients with estimated glomerular filtration rate (eGFR) $<30 \mathrm{~mL} /$ minute. Similarly, the combination of sofosbuvir and ledispavir (a HCV NS5A inhibitor) is currently not recommended in patients with severe renal impairment $(<30 \mathrm{~mL} /$ minute), or ESRD. However, in a preliminary phase $2 \mathrm{~b}$ study including 40 patients infected with HCV G1 and G3 with eGFR $<30 \mathrm{~mL} /$ minute (EKD stage 4), presented at the 2014 Annual Liver Meeting (AASLD, Boston November 2014), Gane et al. have explored the safety and the pharmacokinetics of a different schedule of sofosbuvir (200 mg QD and GS-331007). The authors found: (1) similar virologic response compared to patients with normal renal function; (2) similar blood exposure of the two drugs; (3) slightly improved eGFR during therapy; and (4) satisfactory SVR rates at 4 and 12 weeks. They concluded that sofosbuvir, $200 \mathrm{mg} /$ daily, and ribavirin are relatively well tolerated in patients with severe renal impairment, with exacerbation of anemia due to ribavirininduced hemolysis.

DAAs other than sofosbuvir show potentially safer therapeutic profiles in patients with KD. Simeprevir, a spe- p0215 cific NS3 protease inhibitor, is highly albumin bounded in serum and hence predominantly excreted in bile, rather than in urine. The same occurs for daclatasvir, another HCV inhibitor of NS5A. Therefore, both simeprevir and daclatasvir, although not yet formally studied in patients with severe KD, can reasonably be used in patients with eGFR $<30 \mathrm{~mL} /$ minute, without requiring dose adjustment with respect to the conventional doses (150 mg and $60 \mathrm{mg}$ /daily, respectively). Also paritaprevir (an NS3-4A protease-inhibitor), ombitasvir (a NS5A inhibitor), and dasabuvir (a nonnucleotide NS5B polymerase inhibitor) are predominantly excreted in feces, and have a minimal renal clearance. Thus, their combination could also be safely used, without dose adjustments, in patients with moderate or severe renal disease, but it remains unknown whether this widely prescribed drug combination can be used in those under HD.

Based on the available data, current guidelines of the European Association for the Study of the Liver recom- p0220 mend that all patients under HD, particularly those who are candidates for KT, should be considered for antiviral therapy, preferably using IFN-free schedules. Since simeprevir, daclatasvir, and the combination of ritonavirboosted paritaprevir, ombitasvir, and dasabuvir are mainly excreted through the biliary route, these drugs should be preferably used in patients with severe renal disease. Conversely, sofosbuvir should not be used in these patients until more data will become available. However, the optimal doses of all these drugs in patients under HD are unknown and therefore all they should be used with extreme caution and only in life-threatening conditions. Similarly, no recommendations can be currently given for the use of DAAs in KT recipients, although it is likely that it will become soon possible to cure HCV in these patients using DAAs not interfering with immunosuppressive drugs. Several studies are currently under way to test the safety and efficacy of different DAAs and their combinations in patients under HD as in KT recipients with HCV infection. Their results, expected by the end of 2015 or mid-2016, are greatly awaited.

\section{References}

1. World Health Organization. Hepatitis C. Available at: http://www.who.int/mediacentre/factsheets/fs164/en/2015 [accessed 06.06.15].

2. Li CG, Ferrantelli A, Bono L, et al. Incidence of hepatitis $C$ virus infection in patients with chronic kidney disease on conservative therapy. Int J Infect Dis 2011;15:e514

3. Yorioka Y, Miyakawa N, Yoshizawa Y, Hepatitis H. C virus infection in 2,744 hemodialysis patients followed regularly at nine centers in Hiroshima during November 1999 through February 2003. J Med Virol 2005;76:498-502.

4. Hinrichsen H, Leimenstoll G, Stegen G, Schrader H, Fölsch UR, Schmidt WE, PHV Study Group. Prevalence and risk factors of hepatitis C virus infection in haemodialysis patients: a multicentre study in 2796 patients. Gut 2002;51:429-33.

5. Stempel CA, Lake J, Kuo G, Vincenti F. Hepatitis C-its prevalence in end-stage renal failure patients and clinical course after kidney transplantation. Transplantation 1993;55:273.

6. Fabrizi F, Lunghi G, Ganeshan SV, Martin P, Messa P. Hepatitis C virus infection and the dialysis patient. Semin Dial 2007;20:416-22.

7. Okoh EJ, Bucci JR, Simon JF, Harrison SA. HCV in patients with end-stage renal disease. Am J Gastroenterol 2008;103:2123-34.

8. Liu CH, Kao JH. Treatment of hepatitis C virus infection in patients with end-stage renal disease. J Gastroenterol Hepatol 2011;26:228-39.

9. Singh N, Neidlinger N, Djamali A, et al. The impact of hepatitis C virus donor and recipient status on long-term kidney transplant outcomes: University of Wisconsin experience. Clin Transplant 2012;26:684-93. 
10. de Oliveira Uehara SN, Emori CT, da Silva Fucuta Pereira P, et al. Histological evolution of hepatitis C virus infection after renal transplantation. Clin Transplant 2012;26:842-8.

11. Fabrizi F, Martin P, Dixit V, Bunnapradist S, Dulai G. Hepatitis C virus antibody status and survival after renal transplantation: metaanalysis of observational studies. Am J Transplant 2005;5:1452-61.

12. Rostami Z, Nourbala MH, Alavian SM, Bieraghdar F, Jahani Y, Einollahi B. The impact of Hepatitis C virus infection on kidney transplantation outcomes: a systematic review of 18 observational studies: the impact of HCV on renal transplantation. Hepat Mon 2011;11:247-54.

13. Fabrizi F, Martin P, Dixit V, Messa P. Meta-analysis of observational studies: hepatitis C and survival after renal transplant. J Viral Hepat 2014;21:314-24.

14. Morales JM, Fabrizi F. Hepatitis C and its impact on renal transplantation. Nat Rev Nephrol 2015;11(3):172-82.

15. Baid-Agrawal S, Pascual M, Moradpour D, Somasundaram R, Muche M. Hepatitis C virus infection and kidney transplantation in 2014: what's new? Am J Transplant 2014;14(10):2206-20.

16. Kidney Disease: Improving Global Outcomes (KDIGO). KIDGO KDIGO clinical practice guideline for the prevention, evaluation and treatment of hepatitis C in chronic kidney disease. Kidney Int 2008;73(Suppl. 109):S1-99.

17. Fabrizi F, Lunghi G, Dixit V, Martin P. Meta-analysis: antiviral therapy of hepatitis C virus-related liver disease in renal transplant patients. Aliment Pharmacol Ther 2006;24:1413-22.

18. Fabrizi F, Dixit V, Martin P, Messa P. Combined antiviral therapy of hepatitis C virus in dialysis patients: meta-analysis of clinical trials. J Viral Hepat 2011;18:e263-9.

19. Fabrizi F, Dixit V, Messa P, Martin P. Antiviral therapy (pegylated interferon and ribavirin) of hepatitis C in dialysis patients: metaanalysis of clinical studies. I Viral Hepat 2014:21:681-9.

20. Kidney Disease: Improving Global Outcomes (KDIGO) Transplant Work Group. KDIGO clinical practice guideline for the care of kidney transplant recipients. Am J Transplant 2009;9(Suppl. 3):S1-155.

21. Eason JD, Gonwa TA, Davis CL, Sung RS, Gerber D, Bloom RD. Proceedings of consensus conference on simultaneous liver kidney transplantation (SLK). Am J Transplant 2008;8:2243-51.

22. Nadim MK, Sung RS, Davis CL, et al. Simultaneous liver-kidney transplantation summit: current state and future directions. Am J Transplant 2012;12:2901-8.

23. Mandal AK, Kraus ES, Samaniego M, et al. Shorter waiting times for hepatitis C virus seropositive recipients of cadaveric renal allografts from hepatitis $\mathrm{C}$ virus seropositive recipients of cadaveric renal allografts from hepatitis $\mathrm{C}$ virus seropositive donors. Clin Transplant 2000;14(4 Pt 2):391-6.

24. Lanini S, Abbate I, Puro V, et al. Molecular epidemiology of a hepatitis C virus epidemic in a haemodialysis unit: outbreak investigation and infection outcome. BMC Infect Dis 2010;10:257.

25. Izopet J, Sandres-Sauné K, Kamar N, et al. Incidence of HCV infection in French hemodialysis units: a prospective study. J Med Virol 2005;77:70-6.

26. Jadoul M, Poignet JL, Geddes C, et al. The changing epidemiology of hepatitis C virus (HCV) infection in haemodialysis: European multicentre study. Nephrol Dial Transplant 2004;19:904.

27. Mangia A, Burra P, Ciancio A, et al. Hepatitis C infection in patients with chronic kidney disease. Int J Artif Organs 2008;31:15.

28. Su Y, Norris JL, Zang C, Peng Z, Wang N. Incidence of hepatitis C virus infection in patients on hemodialysis: a systematic review and meta-analysis. Hemodial Int 2013;17:532-41.

29. Jadoul M, Poignet JL, Geddes C, et al. The changing epidemiology of hepatitis C virus (HCV) infection in haemodialysis: European multicentre study. Nephrol Dial Transplant 2004;19:904-9.

30. Johnson DW, Dent H, Yao Q, et al. Frequencies of hepatitis B and C infections among haemodialysis and peritoneal dialysis patients in Asia-Pacific countries: analysis of registry data. Nephrol Dial Transplant 2009;24:1598-603.

31. Arenas MD, Sánchez-Payá J, Muñoz C, et al. Nosocomial transmission of the hepatitis C virus in hemodialysis: monitors, personnel, or both? Nefrologia 2001;21:476-84.

32. Pereira BJ, Levey AS. Hepatitis C virus infection in dialysis and renal transplantation. Kidney Int 1997;51:981-99.

33. Jadoul M, Cornu C, van Ypersele de Strihou C. Incidence and risk factors for hepatitis C seroconversion in hemodialysis: a prospective study. The UCL Collaborative Group. Kidney Int 1993;44:1322-6.

34. KDIGO clinical practice guidelines for the prevention, diagnosis, evaluation, and treatment of hepatitis $\mathrm{C}$ in chronic kidney disease. Kidney Int Suppl 2008:109: S1.

35. Bergman S, Accortt N, Turner A, Glaze J. Hepatitis C infection is acquired pre-ESRD. Am J Kidney Dis 2005;45:684-9.

36. Gallego E, López A, Pérez J, et al. Effect of isolation measures on the incidence and prevalence of hepatitis C virus infection in hemodialysis. Nephron Clin Pract 2006;104:c1-6.

37. Nampoory MR, Gupta RK, Johny KV, et al. Organ-transmitted HCV infection in kidney transplant recipients from an anti-HCV negative donor. Transplant Proc 1999;31:3207.

38. Espinosa M, Martin-Malo A, Alvarez de Lara MA, Soriano S, Aljama P. High ALT levels predict viremia in anti-HCV-positive HD patients if a modified normal range of ALT is applied. Clin Nephrol 2000;54:151-6.

39. Al-Freah MA, Zeino Z, Heneghan MA. Management of hepatitis C in patients with chronic kidney disease. Curr Gastroenterol Rep 2012;14:78-86.

40. Wolf PL, Williams D, Coplon N, Coulson AS. Low aspartate transaminase activity in serum of patients undergoing chronic hemodialysis. Clin Chem 1972;18:567-8.

41. Ghany MG, Strader DB, Thomas DL, Seeff LB. Diagnosis, management, and treatment of hepatitis C: an update. Hepatology 2009;49:1335.

42. Khan N, Aswad S, Shidban H, et al. Improved detection of HCV Infection in hemodialysis patients using a new HCV RNA qualitative assay: experience of a transplant center. J Clin Virol 2004;30:175-82.

43. Bastos DO, Perez RM, Silva IS, et al. Transcriptionmediated amplification (TMA) for the assessment of viremia in hemodialysis patients with hepatitis C. J Med Virol 2012;84:596-600.

44. Liu CH, Kao JH. Treatment of hepatitis C virus infection in patients with end-stage renal disease. J Gastroenterol Hepatol 2011;26:228-39. 
45. Baid-Agrawal S, Schindler R, Reinke P, et al. Prevalence of occult hepatitis C infection in chronic hemodialysis and kidney transplant patients. J Hepatol 2014;60:928-33.

46. Zucker K, Cirocco R, Roth D, et al. Prospective longitudinal assessment of hepatitis C virus infection after renal transplantation. Transplant Proc 1995;27:943.

47. Lok AS, Chien D, Choo QL, et al. Antibody response to core, envelope and nonstructural hepatitis C virus antigens: comparison of immunocompetent and immunosuppressed patients. Hepatology 1993;18:497.

48. Maple PA, McKee T, Desselberger U, Wreghitt TG. Hepatitis C virus infections in transplant patients: serological and virological investigations. J Med Virol 1994;44:43.

49. Preiksaitis JK, Cockfield SM, Fenton JM, Burton NI, Chui LW. Serologic responses to hepatitis C virus in solid organ transplant recipients. Transplantation 1997;64:1775.

50. Allan R, Thoirs K, Phillips M. Accuracy of ultrasound to identify chronic liver disease. World J Gastroenterol 2010;16:3510-20.

51. Baid-Agrawal S, Pascual M, Moradpour D, Frei U, Tolkoff-Rubin N. Hepatitis C virus infection in haemodialysis and kidney transplant patients. Rev Med Virol 2008;18:97-115.

52. Roth D, Gaynor JJ, Reddy KR, et al. Effect of kidney transplantation on outcomes among patients with hepatitis C. J Am Soc Nephrol 2011;22:1152-60.

53. Bravo AA, Sheth SG, Chopra S. Liver biopsy. N Engl J Med 2001;344:495-500.

54. Terjung B, Lemnitzer I, Dumoulin FL, et al. Bleeding complications after percutaneous liver biopsy. An analysis of risk factors. Digestion 2003;67:138-45.

55. Ahmad A, Hasan F, Abdeen S, et al. Transjugular liver biopsy in patients with end-stage renal disease. J Vasc Interv Radiol 2004:15:257-60.

56. Degos F, Perez P, Roche B, et al. Diagnostic accuracy of FibroScan and comparison to liver fibrosis biomarkers in chronic viral hepatitis: a multicenter prospective study (the FIBROSTIC study). J Hepatol 2010;53:1013-21.

57. Schiavon LL, Schiavon JL, Filho RJ, et al. Simple blood tests as noninvasive markers of liver fibrosis in hemodialysis patients with chronic hepatitis C virus infection. Hepatology 2007;46:307-14.

58. Varaut A, Fontaine H, Serpaggi J, et al. Diagnostic accuracy of the fibrotest in hemodialysis and renal transplant patients with chronic hepatitis C virus. Transplantation 2005;80:1550-5.

59. Lin ZH, Xin YN, Dong QJ, et al. Performance of the aspartate aminotransferase-to-platelet ratio index for the staging of hepatitis C-related fibrosis: an updated meta-analysis. Hepatology 2011;53:726-36.

60. Liu CH, Liang CC, Huang KW, et al. Transient elastography to assess hepatic fibrosis in hemodialysis chronic hepatitis $\mathrm{C}$ patients. Clin J Am Soc Nephrol 2011;6:1057-65.

61. Omata M, Kanda $\mathrm{T}, \mathrm{Yu} \mathrm{ML}$, et al. APASL consensus statements and management algorithms for hepatitis $\mathrm{C}$ virus infection. Hepatol Int 2012;6:409-35.

62. Sterling RK, Sanyal AJ, Luketic VA, et al. Chronic hepatitis C infection in patients with end stage renal disease: characterization of liver histology and viral load in patients awaiting renal transplantation. Am J Gastroenterol 1999;94:3576-82.

63. Cotler SJ, Diaz G, Gundlapalli S, et al. Characteristics of hepatitis C in renal transplant candidates. J Clin Gastroenterol 2002;35:191.

64. Vallet-Pichard A, Pol S. Hepatitis C virus infection in hemodialysis patients. Clin Res Hepatol Gastroenterol 2013;37:340-6.

65. Okuda K, Yokosuka O. Natural history of chronic hepatitis C in patients on hemodialysis: case control study with 4-23 years of follow-up. World I Gastroenterol 2004;10:2209-12.

66. Kalantar-Zadeh K, Kilpatrick RD, McAllister CJ, et al. Hepatitis C virus and death risk in hemodialysis patients. J Am Soc Nephrol 2007:18:1584.

67. Butt AA, Skanderson M, McGinnis KA, et al. Impact of hepatitis C virus infection and other comorbidities on survival in patients on dialysis. J Viral Hepat 2007;14:688.

68. Fabrizi F, Takkouche B, Lunghi G, Dixit V, Messa P, Martin P. The impact of hepatitis C virus infection on survival in dialysis patients: meta-analysis of observational studies. J Viral Hepat 2007;14:697.

69. Fabrizi F, Dixit V, Messa P. Impact of hepatitis C on survival in dialysis patients: a link with cardiovascular mortality? J Viral Hepat 2012;19:601

70. Tang SC, Lai KN. Hepatitis C virus-associated glomerulonephritis. Contrib Nephrol 2013;181:194-206.

71. Morales JM, Fabrizi F. Hepatitis C and its impact on renal transplantation. Nat Rev Nephrol 2015;11(3):172-82.

72. Cruzado JM, Carrera M, Torras J, Grinyo JM. Hepatitis C virus infection and de novo glomerular lesions in renal allografts. Am J Transplant 2001;1:171-8.

73. Haas M. Transplant glomerulopathy: it's not always about chronic rejection. Kidney Int 2011;80:801-3.

74. Husain S, Sis B. Advances in the understanding of transplant glomerulopathy. Am J Kidney Dis 2013;62:352-63.

75. Maluf DG, Fisher RA, King AL, et al. Hepatitis C virus infection and kidney transplantation: predictors of patient and graft survival. Transplantation 2007;83(7):853-7.

76. Morales JM, Dominguez-Gil B, Sanz-Guajardo D, Fernandez J, Escuin F. The influence of hepatitis B and hepatitis C virus infection in the recipient on late renal allograft failure. Nephrol Dial Transplant 2004;19:72-6.

77. Baid S, Cosimi AB, Tolkoff-Rubin N, Colvin RB, Williams WW, Pascual M. Renal disease associated with hepatitis C infection after kidney and liver transplantation. Transplantation 2000;70:255-61.

78. Forman JP, Tolkoff-Rubin N, Pascual M, Lin J. Hepatitis C, acute humoral rejection, and renal allograft survival. J Am Soc Nephrol 2004;15:3249-55.

79. Lopez-Medrano F, Fernandez-Ruiz M, Morales JM, et al. Impact of hepatitis C virus infection on the risk of infectious complications after kidney transplantation: data from the RESITRA/REIPI cohort. Transplantation 2011;92:543-9.

80. Toth CM, Pascual M, Chung RT, et al. Hepatitis C virus-associated fibrosing cholestatic hepatitis after renal transplantation: response to interferon-alpha therapy. Transplantation 1998;66:1254-8.

81. Munoz De Bustillo E, Ibarrola C, Colina F, et al. Fibrosing cholestatic hepatitis in hepatitis C virus-infected renal transplant recipients. J Am Soc Nephrol 1998;9:1109-13. 
82. Delladetsima I, Psichogiou M, Sypsa V, Sakellariou S, Hatzakis AJNB. Time of acquisition of HCV infection in renal transplant recipients: a major prognostic factor for disease progression. Clin Transplant 2013;27:72-9.

83. Kamar N, Rostaing L, Selves J, et al. Natural history of hepatitis C virus-related liver fibrosis after renal transplantation. Am J Transplant 2005;5:1704-12.

84. Ridruejo E, Mando OG, Davalos M, Diaz C, Vilches A. Hepatocellular carcinoma in renal transplant patients. Transplant Proc 2005;37:2086-8.

85. Chiang YJ, Wang $\mathrm{HH}$, Liu KL, Chu SH, Lee WC. Hepatocellular carcinoma following renal transplantation: experience in northern Taiwan. Transplant Proc 2008;40:2397-9.

86. Chuang $\mathrm{CH}$, Chien YS, Cheng YT, Chen YT, Hu TH, Hsieh H. Hepatocellular carcinoma in renal transplant recipients. Transplant Proc 2008;40:2392-4.

87. Fabrizi F, Martin P, Dixit V, Bunnapradist S, Kanwal F, Dulai G. Post-transplant diabetes mellitus and HCV seropositive status after renal transplantation: meta-analysis of clinical studies. Am J Transplant 2005;5:2433-40.

88. Cruzado JM, Bestard O, Grinyo JM. Impact of extrahepatic complications (diabetes and glomerulonephritis) associated with hepatitis C virus infection after renal transplantation. Contrib Nephrol 2012;176:108-16.

89. Torres J, Aguado JM, San Juan R, et al. Hepatitis C virus, an important risk factor for tuberculosis in immunocompromised: experience with kidney transplantation. Transpl Int 2008;21:873-8.

90. de Sanjose S, Benavente Y, Vajdic CM, et al. Hepatitis C and non- Hodgkin lymphoma among 4784 cases and 6269 controls from the International Lymphoma Epidemiology Consortium. Clin Gastroenterol Hepatol 2008;6:451-8.

91. Giordano TP, Henderson L, Landgren O, et al. Risk of non-Hodgkin lymphoma and lymphoproliferative precursor diseases in US veterans with hepatitis C virus. JAMA 2007;297:2010-17.

92. Omland LH, Jepsen $\mathrm{P}$, Krarup $\mathrm{H}$, et al. Liver cancer and non- Hodgkin lymphoma in hepatitis $\mathrm{C}$ virus-infected patients: results from the DANVIR cohort study. Int J Cancer 2012;130:2310-17.

93. Scott DR, Wong JK, Spicer TS, et al. Adverse impact of hepatitis C virus infection on renal replacement therapy and renal transplant patients in Australia and New Zealand. Transplantation 2010;90:1165-71.

94. Arcaini L, Merli M, Volpetti S, Rattotti S, Gotti M, Zaja F. Indolent B-cell lymphomas associated with HCV infection: clinical and virological features and role of antiviral therapy. Clin Dev Immunol 2012;2012:6381-5.

95. Covic A, Abramowicz D, Bruchfeld A, et al. Endorsement of the Kidney Disease Improving Global Outcomes (KDIGO) hepatitis C guidelines: a European Renal Best Practice (ERBP) position statement. Nephrol Dial Transplant 2009;24:719-27.

96. Fabrizi F, Bromberg J, Elli A, et al. Reviewed article: hepatitis C virus and calcineurin inhibitor after renal transplantation. Aliment Pharmacol Ter 2005;22:657-66.

97. Morales JM, Campistol JM, Castellano G, et al. Transplantation of kidneys from donors with hepatitis C antibody into recipients with pre transplantation anti HCV. Kidney Int 1995;47:236-40.

98. Fagiuoli S, Bruni F, Bravi M, et al. Cyclosporine in steroid-resistant autoimmune hepatitis and HCV related liver diseases. Dig Liver Dis 2007;39(Suppl. 3):S379-85.

99. Manzia TM, Angelico R, Toti L, et al. Long-term, maintenance MMF monotherapy improves the fibrosis progression in liver transplant recipients with recurrent hepatitis C. Transpl Int 2011;24(5):461-8.

100. Le Pabic H, L'Helgoualc'h A, Coutant A, et al. Involvement of the serine/threonine p70S6 kinase in TGF-beta1-induced ADAM12 expression in cultured human hepatic stellate cells. J Hepatol 2005;43:1038-44.

101. Gäbele E, Reif S, Tsukada S, et al. The role of p70S6K in hepatic stellate cell collagen gene expression and cell proliferation. I Biol Chem 2005;280:13374-82.

102. Tepperman E, Ramzy D, Prodger J, et al. Surgical biology for the clinician: vascular effects of immunosuppression. Can J Surg 2010;53:57-63.

103. Gabardi S, Baroletti SA. Everolimus: a proliferation signal inhibitor with clinical applications in organ transplantation, oncology, and cardiology. Pharmacotherapy 2010;30:1044-56.

104. Andrassy J, Hoffmann VS, Rentsch M, et al. Is cytomegalovirus prophylaxis dispensable in patients receiving an mTOR inhibitor-based immunosuppression? a systematic review and meta-analysis. Transplantation 2012;94(12):1208-17.

105. Soliman A, Fathy A, Khashab S, et al. Sirolimus conversion may suppress viral replication in hepatitis C virus-positive renal transplant candidates. Exp Clin Transplant 2013;11(5):408-11.

106. Shah M, Shankar A, Gee I, et al. A retrospective 15-year review: survival advantage after switching to sirolimus in hepatitis C virus infected liver graft recipients. Aliment Pharmacol Ther 2015;41(4):379-92.

107. Kelly MA, Kaplan M, Nydam T, et al. Sirolimus reduces the risk of significant hepatic fibrosis after liver transplantation for hepatitis C virus: a single-center experience. Transplant Proc 2013;45(9):3325-8.

108. Villamil FG, Gadano AC, Zingale F, et al. Fibrosis progression in maintenance liver transplant patients with hepatitis C recurrence: a randomised study of everolimus vs. calcineurin inhibitors. Liver Int 2014;34(10):1513-21.

109. Bataller R, Brenner DA. Liver fibrosis. J Clin Invest 2005;115:209-18.

110. Fernández-Yunquera A, Ripoll C, Bañares R, et al. Everolimus immunosuppression reduces the serum expression of fibrosis markers in liver transplant recipients. World J Transplant 2014;4(2):133-40.

111. EASL recommendations on treatment of Hepatitis C. J Hepatol. 2015;63(1): 199-236. 


\title{
NON-PRINT ITEM
}

\begin{abstract}
Chronic hepatitis $\mathrm{C}(\mathrm{HCV})$ infection has a high incidence in patients with end-stage renal disease and affects between $11 \%$ and $49 \%$ of the kidney transplant (KT) recipients. After transplantation, HCV infection course is accelerated compared to the general population, and is associated with significant reduction in patient and graft survival. The unfavorable impact of HCV infection on KT survival is mainly related to an accelerated liver disease induced by the use of immunosuppression drugs and specific HVC-related renal disease, including graft glomerulopathy, posttransplant new-onset diabetes, glomerulonephritis, and higher risk of acute and chronic graft rejection. Therefore, the choice of adequate immunosuppression regimen and of antiviral treatment before and after transplantation both play a critical role in HCV-positive KT recipient.
\end{abstract}

Keywords: Epidemiology; extrahepatic complications; glomerulonephritis; hepatic complications after kidney transplant; screening for infection 